\title{
A Method of Detecting Competitors of a Store and Evaluating their Attractiveness in Micro Scale Retail Environment
}

\author{
LEE Jung-Eun*, and SADAHIRO Yukio** \\ * Graduate Student, University of Tokyo, Tokyo 113-8656, Japan \\ ** Department of Urban Engineering, University of Tokyo, Tokyo 113-8656, Japan
}

\begin{abstract}
The availability of data set itself and the method of handling the data set are essential factors to achieve effective decision making in retail marketing, especially for small privately managed retail stores. In the field of retail and marketing geography, attractiveness of a store is analyzed with questionnaire survey and logit model in general. However, the problem is that huge cost is required for the process, which becomes more difficult under a micro scale retail environment. Considering the fact that small retail stores often have their own purchase history data of customers, the cost is reduced if an effective method exists that is applicable using purchase history data only. Hence, the purpose of this paper is focused on evaluating and detecting competitors of a small retail store, with limited data availability, to understand the status of its market area from the geographical aspect by clarifying where its own strong competitors are located. The method uses a probabilistic store choice model, which is usually estimated from the data of consumers' store choice behavior collected by a questionnaire survey. Instead of such detailed but costly data, this paper uses actual sales data of the target store to estimate the model. The method is applied to simulated choice behavior, then, to actual data based on the findings understood from the simulated choice behavior analysis. Results show that the method effectively detects strong competitors of a store. Furthermore, the result may provide a guideline for the store to establish an effective marketing strategy.
\end{abstract}

Key words: GIS marketing, Store choice model, Spatial analysis

\section{Introduction}

In retail geography, spatial structure of retailing and the underlying behavior of consumers have drawn much attention among geographers (Okumoto and Hayasida 2004: 62-67). Numerous studies have been done in retail geography to describe and understand the purchase behavior of consumers.

The method of analysis heavily depends on the scale of research interest. At a global scale, analysis of the distribution of stores and their types is often effective. For instance, the types of stores in a retail cluster depend on its size typically, represented by the number of stores or the area of cluster (Dawson 1980; Berry et al. 1988: 259-287). Small clusters often consist of grocery stores while large clusters may contain supermarkets and department stores. This im- plies that the size of retail clusters affects the choice of shopping destination of consumers, which is caused by their propensity for one-stop shopping. Analysis can be done not only by a descriptive approach but also by using spatial models such as the gravity model. At a local scale, however, analysis not only of the spatial data of stores but the behavioral data of consumers is necessary as well. Through questionnaire surveys, geographers collect the data of consumers' store choice behavior and describe them by using disaggregate spatial choice models such as the logit model (McFadden 1974, 1977; Ben-Akiva and Lerman 1985; Fortheringham 1988; Yano 1992). This enables us to evaluate the effect of detailed attributes of stores, traffic conditions of shopping, preferences of individual consumers, and so forth, which cannot be analyzed in detail with the approach of global scale mentioned earlier. 
In recent years, the interest of geographers has moved to the practical utilization of the result of analysis in retail geography, which is called marketing geography (Huff 1963; Davies 1976: 198-231; Dawson 1980: 95-155; Jones and Mock 1984; Jones and Simmons 1990; Sato 1998). Marketing geography enables us to use this approach as a practical utilization of result analysis. Even more, with the emergence of GIS, attention has been focused on micro scale marketing of stores in marketing geography, which permits store owners to devise effective marketing strategies. Another important point for practical use of retail geography is not to neglect the consumer and the consumption process, which are essential factors for marketing strategy and understanding the purchase behavior of consumers. Such a concept of new retail geography provides a different understanding of space as strategic, open to manipulation and production (Blomley 1994; Wrigley and Lowe 2002).

One of the effective ways of implementing micro scale marketing strategy is a microscopic quantitative analysis of customers' purchase activity. From the practical point of view, a key to successful marketing for store owners is to evaluate the attractiveness both of their own stores and competing ones. Estimation of attractiveness of stores is possible if the data of the location and attributes of stores and consumers' purchase history are available. For instance, Yano (2003) use shopping OD matrix generated by consumers' purchase behavior data of several stores in a certain market area gained by surveying consumers directly. The derived model permits us to evaluate the attractiveness of each store quantitatively. A method of spatial-microsimulation is also suggested to understand purchase behavior of consumers and spatial flow of consumers' expenses by each lifecycle group (Nakaya and Hanaoka 2003).

Unfortunately, collection of consumers' purchase history data is very costly since it requires a questionnaire survey including details of each household. In a practical sense, it is almost impossible to get these essential components for modeling consumers' purchase activity, especially for small privately managed retail stores. In such a situation, it often happens that only its own purchase history data is available in the real world, especially under micro scale retailing environment. For this practical reason, a useful analyzing method is required for the limited spatial data availability.

When the data accessibility is limited, it is not possible to explain consumers' purchase activity directly in detail by a spatial choice model such as the logit model. Thus, this study proposes a new method of measuring the attractiveness of stores and detecting strong competitors of a store from the purchase history data of a store and the spatial data of its surroundings. Using only purchase history data in the analysis is an effective approach for small retail stores to decrease the cost of obtaining data. The result gives important information in market area analysis and provides easier understanding of the sales distribution status for a certain store in the market area. For instance, where the value of sales distribution is low, then existence of competitors is a major reason among possible factors.

In the next chapter, categories of store choice model and the approach to it which is considered in this study are explained. Chapter 3 introduces the methodology of detecting strong competitors of a store which is used in this study, then, method application to simulated choice behavior and actual data is discussed with calculation results in chapter 4 for the model evaluation. Finally, this paper concludes and summarizes the contents of the study in chapter 5 .

\section{Store Choice Model}

\section{Enquired spatial data for analysis}

The goal of this research, again, is to evaluate and detect competitors of a store by using purchase history data of the store. There are several similar existing approaches for such a goal. In the field of area marketing, Ito (2003) uses competition grade as a measure to distinguish the power of stores. It is defined as the sum of areas where the virtual market area of a store is overlapped to a mesh data format map. In addition, the relationship between competition grade and land price which is necessary to launch a new store in market area is considered as well. There is a different concept of compe- 
tition grade proposed by Kobayashi Management Research Institute Ltd. ${ }^{1}$ Competition grade is defined as a ranking system that gives points on several factors including the distance from one's own store, sales status of competitor, target consumer, the history of competitors. There are numerous commercial packages made for such a goal.

The approaches of Ito (2003) and Kobayashi Management Research Institute Ltd. ${ }^{2}$ are focused on finding strong competitors by using the measure of competition grade. Required data list for these approaches are land price map, and a direct survey of competitors' status which are required for the analysis and very costly for data acquisition.

However, this is the biggest problem for small stores in micro scale retail environment, and we are focusing on dealing with this matter in this study. Instead of fully describing the consumers' behavior, this paper aims to measure the attractiveness of competing stores for a particular store to detect its strong competitors. Though we cannot fully evaluate the effect of various factors on store choice, it is practically effective if we can detect strong competitors in marketing planning.

For the analysis, here, the sales data of a certain store and the location of its competitors, which are generally available in micro scale retail environment, are used. To do this, the following three terms are defined to distinguish the other among all stores in the region of the market. First, 'the target store' is defined as a certain store that has its purchase history data of customers. Second, the term, 'potential competitors', indicates the stores located in the region having a possibility to affect the sales of the target store. Third, 'actual competitors' (or 'strong competitors') show the stores located in the region having great effect on the sales of the target store. The goal of this research, in other words, is to extract the actual competitors of the target store.

\section{Modelling store choice behavior}

Following the conventional approach to the analysis of micro scale store choice behavior, this paper adopts the multinomial logit model to explain the consumers' choice behavior (Ben-Akiva and Lerman 1985) which shows the probability of a consumer choosing the target store among all stores in the market area. Then, the probability of consumers' choice behavior is defined in the following equation.

$$
\begin{aligned}
& p_{i}(k)=\frac{A_{i} \exp \left(-\alpha d_{k i}\right)}{\sum_{j} A_{j} \exp \left(-\alpha d_{k j}\right)} \\
& 0 \leq p_{i}(k) \leq 1, \quad \sum_{i \in C_{n}} p_{i}(k)=1, \quad j \in C_{n}
\end{aligned}
$$

In Equation (1), $p_{i}(k)$ denotes the probability of store $i$ being chosen by consumers in location $k$. $C_{n}$ indicates a feasible choice set of stores in the region, $j$ represents the feasible number of choices, the number of stores in this case, and the term $A_{i}$ shows a representative component of total utilities of store $i$.

Equation (1) assumes that the probability $p_{i}(k)$ is proportional to the attractiveness of store $i$ indicated as $A_{i}$ and is in inverse proportion to $d_{k i}$, the distance between a consumer $k$ and store $i$. Generally, the attractiveness of a store consists of many hidden factors that affect the value of the attractiveness in the real marketing situation. Nevertheless, the detailed data list which determines the impact of each store, key features such as marketing approach, reputation, credit managements and others, are not generally easily accessible for small retail stores. Thus, here, $A_{i}$ is defined as a relative measure representing the degree of attracting more consumers to store $i$.

For these reasons, it is difficult to estimate the logit model directly by using Equation (1), since the model requires the probability distribution of choosing each store in a region and the attractiveness of all stores listed in the choice set. The major reason for the problem lies in the lack of practical value of attractiveness of a store and those of key features for the attractiveness as well. Thus, it is not easy to estimate the model where unknown parameters such as $A_{i}$, the attractiveness of store $i$ and the distance parameter $\alpha$ are included in the Equation (1).

\section{Methodology}

As described in the previous section, it is not possible to solve Equation (1) with its original 
definition since the attractiveness of each store is not given as input data. Thus it is required to propose a method for estimating the logit model indirectly due to unknown parameters.

The object of the method is to estimate the value of unknown parameters by using the following equations. Equation (2) describes the value which is close to the actual sales of store $i$ to the consumers in the spatial unit $k$ notated as $W_{k}$, and the term on the right side of the equation includes unknown parameters that should be estimated. By using these two equations below, the value of unknown parameters is estimated where the square error calculated in Equation (3) is at minimum.

$$
\begin{aligned}
& W_{k}=\frac{A_{i} \exp \left(-\alpha d_{k i}\right)}{\sum_{j} A_{j} \exp \left(-\alpha d_{k j}\right)} \cdot M n_{k} \\
& \text { s.t. } \sum_{j=1}^{\mathrm{N}} A_{j}=1, \quad \forall A_{j} \geq 0, \quad i \in j \\
& E=\min \sum_{k}\left\{P_{i}(k)-W_{k}\right\}^{2}
\end{aligned}
$$

If it is assumed that store $i$ is the target store, then, $p_{i}(k)$, the actual sales of store $i$ to the consumers in the spatial unit $k$, of which the market area is divided into mesh data format, can be calculated from the purchase history data of the store. Even though the value itself is not the same as the probability of store choice model, it can be said that the sales amount is equivalent to the probability of choosing the target store, since these two are proportional to each other and can be represented as the degree of the probability attracting consumers to the target store. The number of consumers in $k$, which is notated as $n_{k}$ in Equation (2), can be estimated from demographic data, for instance, with the assumption that it is proportional to the population count of a certain age class.

Therefore, estimation of the model is equivalent to solving Equation (3) where $E$ is at minimum. Then, the value of parameters $A_{j} \quad(j=1$, $\cdots, N$ ) which represents the attractiveness of store $j$ and $M$ that indicates the average purchase amount of consumers can be estimated.

As it is defined in Equation (3), estimated value of unknown parameter $A_{j}$ and $M$ are determined where the square error of two terms $p_{i}(k)$ and $W_{k}$ is the minimum. With the estimated result, it is possible to extract strong competitors of the target store by comparing the value of $A_{j}$ for all $j$. The larger the value of $A_{j}$ is, the stronger the effect of store $j$.

The next process is method application for the evaluation of the proposed method, which is applied to simulated choice behavior first and then to actual data step by step. Application to simulated choice behavior is required for evaluation of the model in terms of understanding the influence of spatial factors and attractiveness of stores with smaller number of stores and larger number of stores. Where smaller number of stores is tried, it is possible to focus on understanding which is the important spatial factor while precise analysis on the attractiveness of stores is available with a larger number of stores. Then, method evaluation of actual data is tried to figure out how the method explains the real situation closely by showing reasonable results.

\section{Applications}

Method application for performance evaluation of the model is conducted in two steps in this study. First, in order to evaluate various factors influencing the performance of the method, it is applied to the analysis of simulated choice behavior. In simulated environments, unlike real ones, influential factors can be fully controlled so that we can evaluate each factor separately without being disturbed by the combination of multiple factors. Second, to test whether the method works in a more realistic environment, it is evaluated by using actual delivery data based on the findings from the simulated process. In this trial, the goal is to grasp how closely the model explains the actual data that is already evaluated in the step of simulated choice behavior.

Since there is no guideline for influential factors in data which will be used, data of simulated choice behavior is generated. For this reason, it is necessary to generate virtual data to calculate $p_{i}(k)$, virtual sales data of store $i$ to the consumers in the spatial unit $k$ since there is no sample data to evaluate the method before applying it to actual data. As a result, then, unknown parameters such as $A_{j}$ and $M$ are deter- 
mined for generation of virtual data. Then, the goal of the next step in evaluating simulated choice behavior is to see how closely those parameters are estimated by the method. In addition, the effect of spatial factors on estimated result is considered as well. This process is expected to give detailed information on how correctly the model works. Such simulated process is indispensable in this study since there is no existing approach for evaluating the method with limited accessibility to obtaining data other than sales data of a store and the location of its competitors.

Second, the model is evaluated by using actual delivery data based on the findings from the simulated process. In this trial, the goal is to grasp how closely the model is able to explain the actual data that is already evaluated in the step of simulated choice behavior. The value of parameters, especially $A_{j}$, the attractiveness of store $j$, is not known in real world situation, only the value of $p_{i}(k)$, actual sales of store $i$ to the consumers in the spatial unit $k$, is known by different time periods during open hours and their integrated version. Thus, the goal of model evaluation with actual delivery data is to see how the estimated result closely reflects the actual situation of market area where the square error of $p_{i}(k)$ and $W_{k}$ in Equation (3) is at minimum. In this process, not only the correctness of estimated value, but also the effect of spatial factors described in simulated process is discussed for method evaluation.

\section{Method application to simulated choice behavior}

The method is applied to simulated choice behavior for the model evaluation. The object is to comprehend how the proposed method works with the proposed model under various conditions of retail marketing environment factors such as the number of competitors, the distance between the target store and competitors and so on.

The flow of method application is described in Figure 1. First, the store choice behavior of consumers is specified by using a logit model. Second, the location and attractiveness of stores are determined in order to evaluate these factors in terms of the performance of the method. Third,

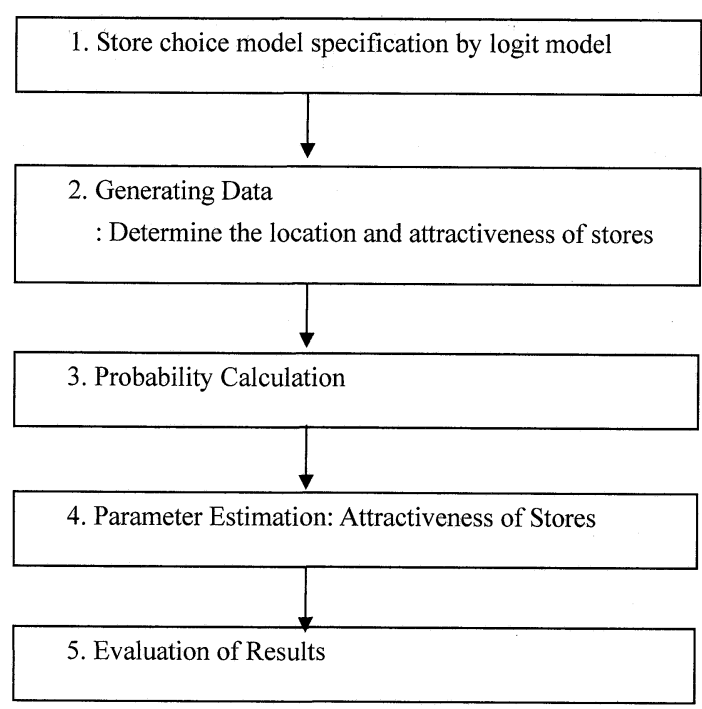

Figure 1. The flow of method application for simulated choice behavior.

the probability of choosing a store is calculated with the details defined in the previous steps. Fourth, estimation of the parameters is done based on the probability calculated in the previous step. This step is to understand how the method works and what factors affect the performance of the method. In the final step, the result is evaluated.

Method application is tried with a smaller number of stores first, then a larger number of stores. By limiting the number of stores we can focus on the effect of spatial factors in the performance of the method, which includes relative distance and direction of competitors. Then, method application with the larger number of stores is tried using only stronger spatial factor known from the method application with the smaller number of stores. The result of method application with the larger number of stores is expected to be a guideline for that of actual data.

For method application for both smaller and larger number of stores, there are two pairs of store attractiveness used in calculation as correct value. The reason is to evaluate the performance of the proposed method. 


\section{Method application with smaller number of stores}

Method application to simulated choice behavior is conducted with a smaller number of stores first. Where the number of stores is small, the number of variations in the attractiveness of stores is relatively small, while it is possible to understand the characteristics of other spatial factors such as relative direction, relative distance among stores. In this step, it is an important task to understand which spatial factor is more influential among given ones. This provides a guide line for further analysis where the number of stores increases. For the model evaluation, testing cases are generated by the spatial configuration of the target store and its competitors. First, three options are given for the distance between the target store and its competitor. $N$ is for near, $M$ is for moderate distance, and $F$ is for far. These options are represented as relative distance. As it is drawn in Figure 2, the option $N$ (Near) is set as a basic measure of distance. Thus, the option $M$ (Moderate) is two times of $N$, and $F$ (Far) is three times of $N$. Second is the relative direction of the competitors' location. This option is considered when the market area is divided into two parts and the target store is located in the middle of them. The value of the direction is given as either same or opposite. If competitors are located in the same part of the market area being divided, then their direction is the same, and if they are located in different parts, then the value of opposite is assigned. For example, the market area is divided into two parts by a dotted line in Figure 2. Then, stores 1 and 2 are in the same direction and store 3 is in the opposite direction when compared with stores 1 and 2 here.

To see how the method works, there are three measures used for result analysis; 1) rank accuracy of all stores, 2) the strongest competitor, and 3) Mean Square Error (MSE).

The measure, rank accuracy of all stores, is to see whether the rank of all stores is correctly estimated or not. If original rank type is given as $1-2-3$, then only the case that estimated result of rank type 1-2-3 is counted as a correct result.

As for the measure of the strongest competitor, it is used to check the rank accuracy among

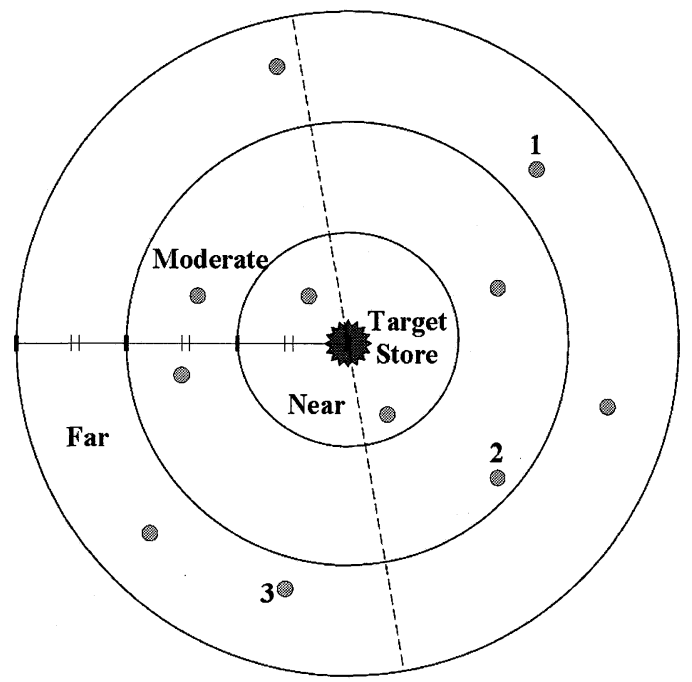

Figure 2. Relative distance and direction options of competitors.

competitors only. In Table 1, for instance, (5, 3, 2) indicates where there are two competitors and a target store. The first figure which is ' 5 ' indicates the attractiveness of target store and other two, ' 3 ' and '2', represent those of competitors. The original rank for the stores is 1-23. Then, the rank types 1-(2-3), 2-(1-3) or 3-(12) shows where the strongest competitor is correctly estimated by the relative rank between two competitors, indicated as the last two numbers in each rank type being put in round brackets, regardless of the rank of the target store.

Now, the measure of Mean Square Error (MSE) is used to evaluate the closeness of estimated value of each parameter to the correct one. The value of MSE is calculated by taking the average of MSE for total samples of each case.

Concerning the method application of simulated choice behavior with smaller number of stores, two sets of correct values for attractiveness of three stores are given for the calculation. Those two sets of attractiveness of stores have different variance with their values; the variance of one set is bigger than that of the other. By this approach, it is able to check how the method works when the variance of attractiveness of stores are given differently. The results are explained in Tables 1 and 2, respectively.

Table 1 describes the result of calculation 
Table 1. The result of estimation by distance and direction (1)

\begin{tabular}{|c|c|c|c|c|c|}
\hline \multirow{2}{*}{$\begin{array}{l}\text { Case_ID } \\
(5,3,2)\end{array}$} & \multirow{2}{*}{$\begin{array}{c}\text { Distance \& } \\
\text { Direction }\end{array}$} & \multicolumn{3}{|c|}{ Estimated Cases of Rank Accuracy } & \multirow[b]{2}{*}{ Avg_MSE } \\
\hline & & All Stores & $\begin{array}{l}\text { Strongest } \\
\text { Competitor }\end{array}$ & $\begin{array}{c}\text { Total Number of } \\
\text { Feasible Solutions }\end{array}$ & \\
\hline $2-1$ & $N / N / S$ & 30 & 9 & 55 & 0.089 \\
\hline $2-2$ & $N / N / O$ & 10 & 16 & 52 & 0.246 \\
\hline $2-3$ & $N / M / S$ & 13 & 9 & 35 & 0.246 \\
\hline $2-4$ & $N / M / O$ & 21 & 14 & 53 & 0.129 \\
\hline $2-5$ & $N / F / S$ & 12 & 12 & 32 & 0.289 \\
\hline $2-6$ & $N / F / O$ & 23 & 17 & 67 & 0.131 \\
\hline $2-7$ & $M / M / S$ & 23 & 28 & 97 & 0.070 \\
\hline $2-8$ & $M / M / O$ & 22 & 30 & 100 & 0.075 \\
\hline $2-9$ & $M / F / S$ & 18 & 17 & 54 & 0.129 \\
\hline $2-10$ & $M / F / O$ & 20 & 28 & 89 & 0.083 \\
\hline $2-11$ & $F / F / S$ & 22 & 32 & 99 & 0.070 \\
\hline $2-12$ & $F / F / O$ & 20 & 29 & 99 & 0.069 \\
\hline
\end{tabular}

* $N$ : Near, $M$ : Moderate, $F$ : Far, $S$ : Same, O: Opposite.

$*(5,3,2)$ indicates the correct value of attractiveness of each store.

Table 2. The result of estimation by distance and direction (2)

\begin{tabular}{|c|c|c|c|c|c|}
\hline \multirow{2}{*}{$\begin{array}{c}\text { Case_ID } \\
(6,2.5,1.5)\end{array}$} & \multirow{2}{*}{$\begin{array}{c}\text { Distance \& } \\
\text { Direction }\end{array}$} & \multicolumn{3}{|c|}{ Estimated Cases of Rank Accuracy } & \multirow[b]{2}{*}{ Avg_MSE } \\
\hline & & All Stores & $\begin{array}{l}\text { Strongest } \\
\text { Competitor }\end{array}$ & $\begin{array}{l}\text { Total Number of } \\
\text { Feasible Solutions }\end{array}$ & \\
\hline $2-1^{\prime}$ & $N / N / S$ & 17 & 5 & 37 & 0.227 \\
\hline $2-2^{\prime}$ & $N / N / O$ & 26 & 4 & 54 & 0.172 \\
\hline $2-3^{\prime}$ & $N / M / S$ & 9 & 5 & 31 & 0.417 \\
\hline $2-4^{\prime}$ & $N / M / O$ & 35 & 10 & 71 & 0.117 \\
\hline $2-5^{\prime}$ & $N / F / S$ & 8 & 6 & 15 & 0.666 \\
\hline $2-6^{\prime}$ & $N / F / O$ & 32 & 7 & 77 & 0.127 \\
\hline $2-7^{\prime}$ & $M / M / S$ & 44 & 9 & 95 & 0.081 \\
\hline $2-8^{\prime}$ & $M / M / O$ & 45 & 8 & 98 & 0.076 \\
\hline $2-9^{\prime}$ & $M / F / S$ & 26 & 9 & 58 & 0.154 \\
\hline $2-10^{\prime}$ & $M / F / O$ & 56 & 7 & 92 & 0.063 \\
\hline $2-11^{\prime}$ & $F / F / S$ & 39 & 13 & 100 & 0.073 \\
\hline $2-12^{\prime}$ & $F / F / O$ & 45 & 8 & 98 & 0.072 \\
\hline
\end{tabular}

* $N$ : Near, $M$ : Moderate, $F$ : Far, $S$ : Same, $O$ : Opposite.

$*(6,2.5,1.5)$ indicates the correct value of attractiveness of each store.

where the correct values of attractiveness for three stores are assigned as 5, 3 and 2, meaning the original rank type for all stores is 1-2-3. The target store is assumed to be the one with the biggest attractiveness value. The case_ID consists of two figures divided by a hyphen; the first one indicates the number of competitors for the target store and the second one is for the case type differing by various options such as relative direction and distance. There are 1,200 calculations tried in total for all 12 cases. For each case_ID, 100 calculations are done with combi- nation in variations of assigning starting value of variables.

Calculation is tried with different set of attractiveness of stores from previous one having larger variance among the values than that of previous case, this time, the correct values of attractiveness for three stores are $6,2.5$ and 1.5 where the original rank for all stores is 1-2-3. The result of calculation is summarized in Table 2. The target store is assumed to be the one that has the biggest attractiveness value. The case_ID and total number of calculations are de- 
Table 3. The summary of result analysis with small number of stores

\begin{tabular}{|c|c|c|}
\hline Correct Value of Attractiveness of each store & $(5,3,2)$ & $(6,2.5,1.5)$ \\
\hline \multicolumn{3}{|c|}{ Estimated Rank Accuracy by the Number of Calculations } \\
\hline - Strongest Competitors & $475 / 1,200$ & $473 / 1,200$ \\
\hline - All Stores & $234 / 475$ & $382 / 473$ \\
\hline \multicolumn{3}{|l|}{ Relative Direction by MSE } \\
\hline - Same & 0.149 & 0.236 \\
\hline - Opposite & 0.122 & 0.105 \\
\hline \multicolumn{3}{|l|}{ Relative Distance by MSE } \\
\hline - Including $N, M, F$ & 0.188 & 0.288 \\
\hline - Including $M, F$ & 0.083 & 0.087 \\
\hline
\end{tabular}

fined in the same way as they are indicated beforehand.

Estimated results depicted in Tables 1 and 2 are summarized in Table 3 by the number of calculations and spatial configuration.

From the results which are described in Table 3 , two cases of different correct values for small number of stores give similar results with the spatial configuration of the target store and its competitors. The method works better when all competitors are located in the moderate or far distance from the target store than other cases. As for the effect of relative direction, the case where competitors are in opposite direction demonstrates better results. From the point of evaluation measures, the model gives better results in the number of calculations and estimation accuracy indicated by MSE as well where the relative distance is moderate or far, and relative direction is opposite for competitors where the target store is in the middle.

\section{Method application with larger number of stores}

In the previous section, the estimation of simulated choice behavior is tested with smaller number of competitors. In such case, the number of variations in the attractiveness of stores is relatively small while other spatial factors such as relative direction, relative distance among stores, are able to be analyzed and explained by the method. Concerning the influence of spatial factors, in the previous trial, it is known that the method shows better performance where relative distance is either moderate or far, and relative direction is opposite for competitors where the target store is in the middle of divided market area.

After verification of these factors, the focus is moved to the effect of variation in the attractiveness of stores, where the number of stores is larger so that is possible to explain closely to real world situation. From this context, testing the model with larger number of competitors is investigated as well, and details are depicted below.

The number of cases for testing is reduced where the number of stores is increased. Due to increased number of competitors, the number of combinations for generating calculation cases where all options being depicted in the previous section are considered as well would be numerous. However, it is not desirable to deal with all cases since it is a time consuming process. Thus, in this section, a testing case is generated only with distance option of moderate and far which are found to be more effective factors for model evaluation in the test calculation with smaller number of competitors.

The result of analysis with larger number of stores is summarized in Table 4 . The correct vale of attractiveness of each store is given in decreasing order, meaning that the rank is assigned as increasing order. The case_ID consists of two figures and a letter of the alphabet including a hyphen in the middle. For instance, $9 M-1$ indicates that there are nine competitors and the distance option is $M$. And there are two cases of $9 M$ that are different by the correct value for store attractiveness sets being marked as 1 or 2 
Table 4. The result of estimation with larger number of stores

\begin{tabular}{crccc}
\hline & \multicolumn{3}{c}{ Estimated Cases of Rank Accuracy } & Avg_MSE \\
\cline { 2 - 4 } Case_ID & $(1)$ & $(2)$ & Total Number of Feasible Solutions & 0.106 \\
$9 M-1$ & 4 & 1 & 19 & 0.098 \\
$9 M-2$ & 4 & 2 & 52 & 0.026 \\
$9 F-1$ & 16 & 9 & 42 & 0.033 \\
$9 F-2$ & 11 & 7 & & 19 \\
\hline
\end{tabular}

* $M$ : Moderate, $F$ : Far.

In Case_ID, option 1 indicates a set of store attractiveness $(1.75,1.55,1.4,1.3,1.1,0.9,0.7,0.6,0.5,0.2)$ and option 2 represents store attractiveness $(1.8,1.6,1.35,1.2,1.15,0.96,0.8,0.57,0.43,0.14)$.

(1): The number of cases where the rank of first three stores is in increasing order.

(2): The number of cases where the rank value of the first three stores include 1, 2 and 3.

after the hyphen. Since the direction of a competitor is not considered here, only the distance option $M$ and $F$ is attached after the number of competitors.

There are two measures for evaluation of the model being indicated as (1) and (2). (1) is the number of cases where the rank of the first three stores is in increasing order, and (2) is the number of cases where the rank values of the first three stores consist of 1,2 and 3 .

Here, rank accuracy of only three stores is considered. There are two reasons for such an approach. First, it is understood that the method is effective with a smaller number of parameters from the test calculation. Second, the goal of this research is to extract strong competitors among many of them. Since there are nine competitors, it is better to consider estimated rank of top three stores, not all competitors to make clear judgment for result evaluation.

As for MSE value, the values are 0.106 and 0.098 where the relative distance option is $M$. The values with the relative distance option $F$ are 0.026 and 0.033 showing that estimation accuracy is far better, having three or four times of accuracy, than that of the option $M$ since the value of MSE is much smaller than the case of $M$ which shows better method performance. In addition, the number of calculations with accurate results is larger when the relative distance option for competitors is $F$ than when the option is $M$. Thus, summarized result shows that the model estimates the parameter value closer to its correct value when competitors are located at a far distance.
Considering the findings in the description above, applying the method to the purpose of establishing marketing strategy can be utilized in the following cases with reliable correctness. First, extracting reasonable number of strong competitors under retail marketing environment is possible. As a matter of fact, there is no specified threshold for the reasonable number of stores. However, as far as it is known from the calculation with simulated cases, the rank of prior 3 or 4 stores are estimated correctly. From this aspect, it is determined that a reasonable number of strong competitors is 3 or 4 . In addition, such result is independent of spatial configuration of stores and their attributes. Second, there is a possibility of extracting strong competitors that are located at a far distance in the market area. Throughout the calculations of simulated cases, it is understood that the model is able to detect a competitor located at a far distance since the performance of the model shows better accuracy where competitors are far away.

\section{Method application to actual delivery data}

The proposed method is applied to simulated choice behavior at first in the previous section to check the performance of model and impact of factors. From the result, it is found out that spatial factor of relative distance and performance measure of MSE value are major components in explaining the performance of the method. Since the verification process of the method is done with method application to simulated choice behavior, now it is necessary to apply the method to actual delivery data to check whether the method really works correctly 


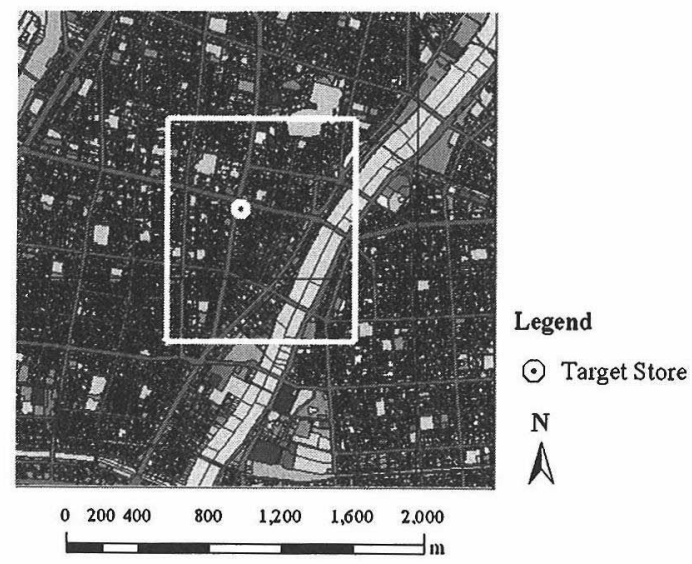

Figure 3. The map of study area.

The area inside the white rectangle indicates the study area.

and reflects real situation of micro scale retail environment as it is.

Before going into method application to actual delivery data, explanation on actual data is represented first. Concerning actual delivery data, delivery data of a noodle store in Tokyo is used as a source. For geographical information aspect, the study area is shown in Figure 3, indicated as an inner area of a brightly lined rectangle, and the target store is located in the middle of the market area marked as an octagon with a dot in the center on the map. The delivery data contain the name and location of customers, ordered item, time and amount of orders in JPY (Japanese Yen), and other detailed information. For example, the average sales of each time period can be summarized as shown in Figure 4. From this figure, only the average sales amount of each open hour period is known. However, there is still more information that can be extracted. Thus, the data are converted into spatial data with delivery history as their attributes.

In Figure 5, the location of the target store and its competitors is shown. The location of each store is plotted on the mesh data which indicates the market area of a target store. By using the mesh data, source data can be converted into spatial data in discrete form as shown in Figures 6 and 7.

Converted data are shown in Figure 6 as the distribution of value indicating sales amount di-

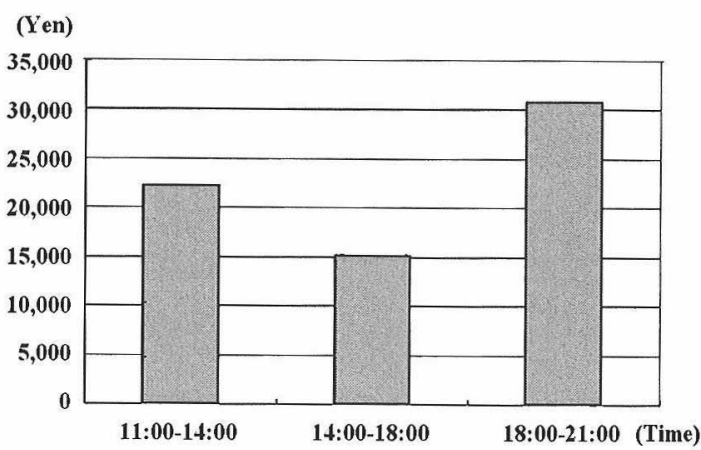

Figure 4 . The sales average by time period.

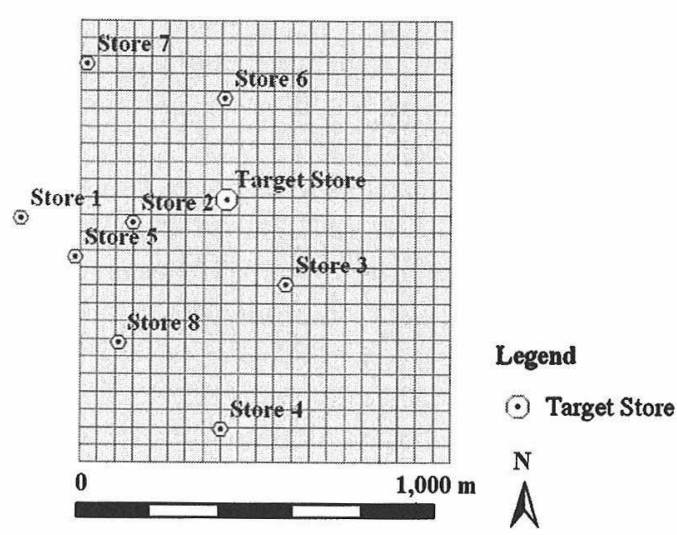

Figure 5. The location of the target store and its competitors.

vided by population among three different periods. The open hours of the target store are divided into three periods. Each cell in the map represents sales amount in JPY (Japanese Yen) unit being divided into population and it is colored by level of the value. From the converted spatial data, it is possible to see how the customers and purchase amount are spatially distributed in the market area.

Estimated attractiveness of stores is depicted as their rank in Figure 6 . It is found that estimated strong competitors are different by time period. For time period of 11:00-14:00 and 14:00-18:00, extracted strong competitors are the same. However, for the time period of 18:00-21:00, the result is different. A possible reason for such a result is in the difference of the distribution of sales amount divided by population. It is clear that the distribution is rela- 
(a) 11:00-14:00

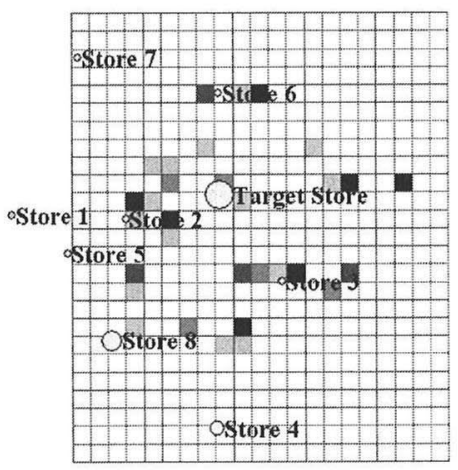

(b) $14: 00-18: 00$

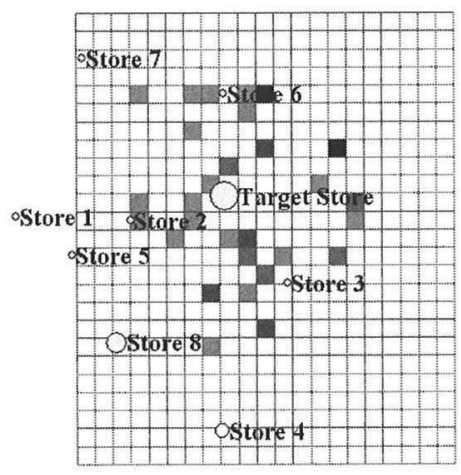

(c) 18:00 - 21:00
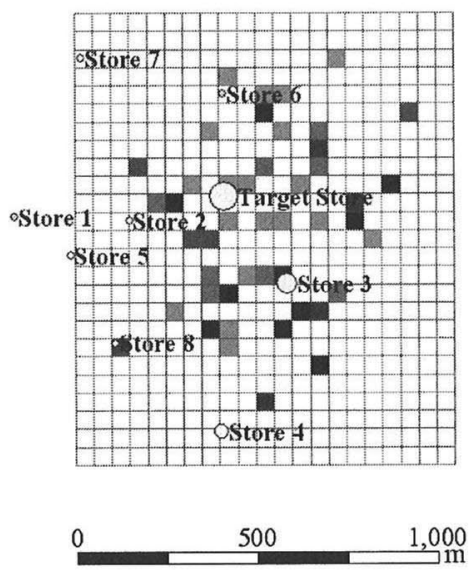

Legend

Yen/Population

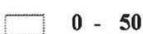

$100-150$

$150-200$

$200-250$

$250-300$

300 - Max

Rank of Stores

( $1^{\text {st }}$

( $2^{\text {nd }}$

O $3^{\text {rd }}$

- $4-9^{\text {th }}$

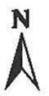

Figure 6. Estimated attractiveness shown by rank of competitors by each time period.

Where the rank is higher, the size of circle indicating each store is larger as well.

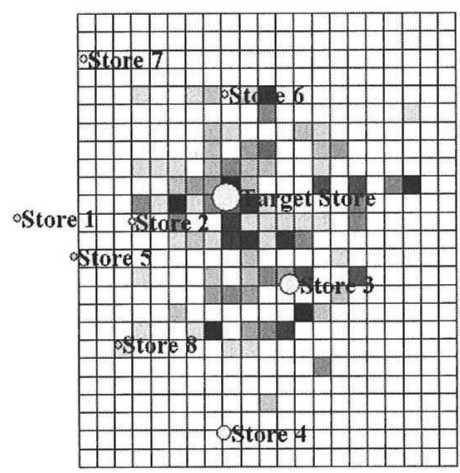

Legend

Yen/Population

$\square \quad 0$ - 100

$\square \quad 100-200$

ए $200-300$

$300-400$

$\square 00-500$

$500-600$

$600-700$

$700-800$

$800-900$

$900-1000$

1000 - 2200

Rank of Stores

$\left(1^{\text {st }}\right.$

(1) $2^{n d}$

$03^{\mathrm{rd}}$

$\circ 4-9^{\text {th }}$

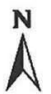

Figure 7. Estimated attractiveness shown by rank of competitors in integrated format.

Where the rank is higher, the size of circle indicating each store is larger as well.

tively sparse with the time period of 11:00-14:00 and 14:00-18:00 and the distribution is dense for time period of 18:00-21:00. Even more, the shape of distribution is similar with the time period of 11:00-14:00 and 14:00-18:00.

In Figure 7, the distribution of sales amount being divided by population is shown in integrated format. In general, the distribution of the actual sales is dense near the target store and it gets sparser where the distance from the target store gets further. However, the distribution is not smooth in general, since there are several hollow points in the region, which is due to the existence of competitors.

Estimated result of attractiveness of each competitor is indicated as rank of stores in Figure 7. Comparing the result with those of Figure 6, the same result is shown during the time period of 18:00-21:00. These two cases have similar sales distribution shape within the market area. Among three different time periods of sales distribution, the first two time periods in the afternoon have the same set of strong competitors where they have similar marketing status; location of consumers and sales distribution. Concerning the time period in the evening, different from other periods in the afternoon, shows the same set of strong competitors is shown as in- 
tegrated data.

To this end, it is able to detect strong competitors by the proposed method of which the result fits the status of each case of actual delivery data where they differ by time periods that are depicted by the distribution of the actual sales of the target store being divided by population and the location of its competitors in the market area. From the above results, as shown in Figures 6 and 7, therefore, it can be said that estimated results fit the actual data. Considering factors mentioned in simulated choice behavior with larger number of stores, it seems that the spatial factor of relative distance matters in extracting strong competitors by proposed model.

When it is assumed that relative distance option $N$ is equal to $150 \mathrm{~m}$, then $M$ is equal to $300 \mathrm{~m}$ and $F$ is equal to $450 \mathrm{~m}$. Since the distances between each estimated strong competitor and the target store, of $320 \mathrm{~m}, 460 \mathrm{~m}$, and $600 \mathrm{~m}$, belong to the distance option of $M$ and $F$, the performance of the model corresponds with both simulated choice behavior and actual delivery data. As for MSE value, 0.0096, 0.0099, 0.0089 are calculated by each time period, 0.0094 with integrated data. MSE values with actual delivery data is significantly smaller, ten times smaller approximately, than those of simulated choice behavior, showing that the model works better with much accuracy. Figure 6 (a) and (b) shows the combination of relative distance is $M / F$ and Figure 6 (c) and Figure 7 denotes $F / F$. Comparing MSE value for each combination, it is understood that the combination of $F / F$ gives better accuracy in estimation.

Concerning spatial factors mentioned in this study, the influence of relative direction is evaluated as well within the combination of relative distance. The influence of relative direction, however, depends on how the market area is divided. In this study, division of the market area is conducted in 1) west-to-east direction and 2) south-to-north direction. In Figure 6 (a) and (b), relative direction between two strong competitors (stores 4 and 8 ) is always in the same direction so that the combination of spatial factors is $M / F / S$ at all times regardless of what direction the market area is divided. Concerning Figure 6 (c) and Figure 7, relative direction be- tween competitors (stores 4 and 3 ) is the same where the market area is divided into west-toeast direction with the combination factors of $F / F / S$ while it is the opposite where the market area is divided into south-to-north direction with the combination factors of $F / F / O$. However, estimated results are not affected by the direction and no changes in MSE value are found.

Therefore, the result of method application to actual data can be summarized that the result shows consistency in terms of relative distance with those obtained from the simulated cases. Unfortunately, the method shows little influence in the result with the spatial factor of relative direction. These findings show that relative distance is the most critical factor that determines the performance of the method.

\section{Conclusions}

In this paper, a method is proposed to estimate the store choice model with limited accessibility of spatial data. Store choice model is specified by logit model and defined as the probability that a consumer chooses a store among many of them. Instead of unavailable spatial data, actual sales data of the target store that is proportional and equivalent to the probability is used, which is integrated from the delivery data of a store in this research.

To comprehend how the proposed method works with proposed model under various conditions of retail marketing environment factors such as the number of competitors, the distance between the target store and competitors and so on, the method is applied to simulated choice behavior for the model evaluation.

Major findings from simulated cases are as follows. First, relative distance between the target store and competitors matters with the performance of the method where the relative distance is either $M$ or $F$. Especially, for both small and large number of stores the method works better with the distance option $F$. Second, relative direction has little influence on the performance of the method; opposite direction shows slightly better performance. Third, the accuracy of the method increases when the number of stores is increased.

Then, the method is applied to actual delivery 
data. It is found that the results of detected strong competitors differ by the distribution of sales amount divided by population difference. Estimated results show the same set of strong competitors where the marketing circumstances such as the location of consumers and sales distribution are similar. Among three different time periods of sales distribution, therefore, the first two time periods in the afternoon have the same set of strong competitors where they have similar marketing status. Concerning the time period in the evening, different from others, the same set of strong competitors is shown as integrated data.

To this end, it is possible to detect strong competitors by the proposed method of which the result fits the status of actual delivery data that are depicted by the distribution of the actual sales of the target store being divided by population and the location of its competitors in the market area.

Concerning spatial factors explained in simulated choice behavior, similar to its results, it seems that the spatial factor of relative distance matters in the calculation of actual data as well. The model shows that strong competitors are located in either combination of relative distance $M / F$ or $F / F$ proofing consistency with the results shown in simulated choice behavior. However, combination of spatial factors where relative direction is added to above combination of relative distance, the result shows no difference. Therefore, relative distance matters but relative direction doesn't, with the proposed method in this study. In addition, MSE values with actual delivery data is significantly smaller, approximately ten times smaller, than those of simulated choice behavior, showing that the model works with better accuracy.

Considering the results described above, it is possible for the store to establish its marketing strategy to gain far better sales than current status. For instance, from the fact that strong competitors differ by each time period, the store may provide different and unique service according to each time period to attract more consumers. Concerning the location of strong competitors, another possible solution may be updating the delivery route. Such instances are the basic components for systemizing regional marketing which satisfies the needs, wants and wishes of consumers in the context of consumers' preference on shopping space. Not only informational systemization on retail marketing should be concerned, but market's lifecycle (Sato 1998) is another important factor as well to consider comprehending how the environment of market area changes for establishing marketing strategy in terms of marketing geography.

The result of this study, from the geographical point of view, helps to describe and understand the status of micro scale retail environment. This corresponds to the characteristics of retail geography, on which it focuses as well.

In recent years, practical use of retail geography and a method of spatial-microsimulation are emphasized as a way of describing and understanding the purchase behavior of consumers. However, the problem of such an approach is that it requires detailed information which is quite costly and practically impossible to obtain under the micro scale retail environment, especially. To resolve such difficulty, this study proposes an alternative method of estimating the store choice model specified by logit model for the analysis of attractiveness of stores where the accessibility to detailed data is limited. From the result, it is found out that information obtained from the proposed method is expected to help a store to devise a more effective marketing strategy and increase its sales over its current status.

\section{Acknowledgements}

This research is financially supported by Research Fellowship of the Japan Society for the Promotion of Science (No.17-11032). Authors thank many anonymous reviewers for their valuable comments.

(Received 3 June 2005)

(Accepted 1 January 2006)

\section{Notes}

1. Kobayashi Management Research Institute Ltd. uses a check list to evaluate the status of competitng stores by grading system. In addition, a report of detailed description of competitors is used as well to compare with the status of a store. Comparing points included in the report are the physical layout and level of service, etc. 
(http://www2s.biglobe.ne.jp/ kobayasi).

2. Op. cit.

\section{References}

Ben-Akiva, M. and Lerman, S. R. 1985. Discrete choice analysis. Cambridge, Mass: The MIT Press.

Berry, B. J. L., Parr, J. B., Epstein, B. J., Ghosh, A. and Smith, R. H. T. 1988. Market centers and retail location: Theory and applications. New York: Prentice Hall.

Blomley, N. K. 1994. Law, space, and the geographies of power, New York: Guilford Press.

Davies, R. L. 1976. Marketing geography: With special reference to retailing. London: Methuen \& Co., Ltd.

Dawson, J. A. ed. 1980. Retail geography. New York: John Wiley \& Sons Ltd.

Fortheringham, A. S. 1988. Consumer store choice and choice set definition, Marketing Science Journal 7(3): 299-310.

Huff, D. L. 1963. A probabilistic analysis of consumer spatial behaviour. In Emerging concepts in marketing, ed. S. D. William, 443-361. Chicago: American Marketing Association.

Ito, H. 2003. Correlation research of the competition grade of a retail store, and the price of land, and application on marketing. Papers and Proceedings of Geographic Information Systems Association 12: 161-164. (JE)

Jones, K. G. and Mock, D. R. 1984. Evaluating retail trading performances. In Store location and store assessment research, ed. R. L. Davis and D. S. Rogers. New York: John Wiley.

Jones, K. and Simmons, J. 1990. The retail environ- ment. London: Routledge.

McFadden, D. 1974. Conditional logit analysis of qualitative choice behavior. In Frontiers in econometrics, ed. P. Zarembka, 105-142. New York: Academic Press.

McFadden, D. 1977. Econometrics models of probabilistic choice. In Structural analysis of discrete data with econometric applications, ed. C. F. Manskiy and D. McFadden, 198-272. Cambridge Mass: MIT Press.

Nakaya, T. and Hanaoka, K. 2003. Retail modeling by spatial micro simulation; survey and research of customers purchase behavior in Kusatsu-City: The second period research 2001-2003, Implementing Facility Allocation Plan Supporting System by GeoComputation, Research Report, 37-56. (J)

Okumoto, K. and Hayasida, H. ed. 2004. Introduction to marketing. Hachioji: Chuo University Press. (J)

Sato, T. 1998. Marketing geography. Tokyo: Doubunkann Shuppan Co., Ltd. (J)

Wrigley, N. and Lowe, M. 2002. Reading retail: A geographical perspective on retailing and consumption spaces. London: Arnold.

Yano, K. 1992. Note on spatial interaction models as a discrete choice model: From entropy maximizing models to multinomial logit models. Notes on Theoretical Geography 8: 55-75. (J)

Yano, K. 2003. Implementation of impact prediction model by using detailed consumers' buying behavior data: Survey and research of customers purchase behavior in Kusatsu-City: The second period research 2001-2003. Implementing Facility Allocation Plan Supporting System by GeoComputation, Research Report: 17-35. (J) 